\title{
LIVRE DEMANDA E SINAIS DE FOME DO NEONATO: PERCEPÇÃO DE NUTRIZES E PROFISSIONAIS DA SAÚDE
}

\section{Fernanda Paula Cerântola Siqueira}

Docente do curso de Enfermagem da Famema - Área da criança. Especialista em Enfermagem Pediátrica pela SOBEP. Mestre na Área de Enfermagem Fundamental EERP-USP. Doutora em Ciências pelo Programa Interunidades EE-USP-SP, Brasil.

\section{Barbara Almeida Santos}

Enfermeira graduada pela Faculdade de Medicina de Marília e R1 Enfermagem Neonatal pela Universidade Estadual de Londrina (UEL), Brasil.

E-mail: bah_almeidas@hotmail.com
RESUMO: O objetivo deste artigo é compreender o conceito de livre demanda e sinais de fome do neonato sob a ótica de nutrizes e profissionais da saúde. Foi realizado um estudo qualitativo com 21 nutrizes e 20 profissionais da saúde que atuam em um hospital materno infantil Amigo da Criança. Os dados foram coletados por meio de entrevistas gravadas e utilizou-se da análise de conteúdo na modalidade temática. Para atingir o objetivo, foram abordados dois temas: em busca do significado de livre demanda e reconhecimento dos sinais de fome do neonato. A partir deles, evidenciou-se que as nutrizes e alguns profissionais desconhecem o real significado de livre demanda e apontam o choro como o principal sinal de fome da criança.

PALAVRAS-CHAVE: Aleitamento Materno; Saúde da Criança; Saúde Materno Infantil.

\section{FREE DEMAND AND HUNGER SIGNALS OF THE NEWBORN: PERCEPTION OF WET-NURSES AND HEALTH PROFESSIONALS}

\begin{abstract}
This paper aims to understand the concept of free demand and hunger signals of the newborn from the perspective of wet-nurses and of health professionals. A qualitative study with 21 wet-nurses and 20 health professionals working in a Child Friendly maternity hospital was performed. The data was collected through recorded interviews and it was used content analysis in the thematic mode. The following subjects were approached: searching the meaning of free demand and recognition of the newborn's hunger signals. From them, It was evidenced that wet-nurses and some professionals do not know the real meaning of free demand and they indicate the cry as main signal of child hunger.
\end{abstract}

KEY WORDS: Breast Feeding; Child Health; Maternal and Child Health.

\section{INTRODUÇÃO}

O aleitamento materno é um ato que não cumpre apenas a função de nutrir, mais que isso, também envolve afeto, vínculo, proteção e uma intensa interação entre mãe e neonato que irão gerar consequências no desenvolvimento emocional e cognitivo da criança (BRASIL, 2015).

O leite humano é o alimento mais completo que pode ser oferecido para crianças até dois anos, sendo fonte natural de anticorpos 
e contendo nutrientes suficientes para o crescimento saudável do neonato, evitando doenças e diminuindo a probabilidade de mortalidade infantil. Em vista disso, é recomendado pela Organização Mundial da Saúde (OMS) que seja oferecido aleitamento materno exclusivo para neonatos até seis meses de idade e que a amamentação seja mantida até, pelo menos, os dois anos de idade com adesão de outros alimentos adequados (OMS, 2002).

A II Pesquisa de Prevalência do Aleitamento Materno nas Capitais Brasileiras e Distrito Federal, que foi realizada no Brasil em 2008 e trata da prevalência do aleitamento materno, mostra que as taxas de prevalência tiveram um considerável aumento, indicando uma porcentagem de $41 \%$ de crianças com até seis meses sendo exclusivamente amamentadas. Em 2006, essa taxa era de 39,8\% (BRASIL, 2009). A análise da influência da situação da amamentação em 1999 sobre o comportamento dos indicadores em 2008 mostra que houve maior progresso nas capitais com pior situação em 1999 e uma menor evolução ou mesmo recuo em locais onde a situação era mais favorável, persistindo diferenças entre as regiões e capitais analisadas (VENANCIO, 2010). Apesar deste progresso, nota-se que o índice ainda está aquém do proposto pela OMS (OMS, 2002). Em Marília, a taxa de prevalência de crianças menores de 6 meses em amamentação exclusiva é de 30\%, sendo inferior à média nacional (BRASIL, 2010).

Uma das medidas políticas adotadas no Brasil no âmbito hospitalar para o incentivo do aleitamento materno é a Iniciativa Hospital Amigo da Criança (IHAC), criada em 1990 pela Organização Mundial da Saúde e pelo Fundo das Nações Unidas para a Infância (OMS, 1990). Essa iniciativa foi incorporada ao Ministério da Saúde em 1992 como ação do Programa Nacional de Incentivo ao Aleitamento Materno (PNIAM) e tem como uma de suas propostas a capacitação e mobilização de profissionais da saúde de maternidades para a mudança de práticas que favoreçam o cumprimento dos "Dez Passos para o Sucesso do Aleitamento Materno" (BRASIL, 2011; OMS, 2002).

Segundo o Ministério da Saúde (BRASIL, 2011), esses passos compreendem: ter uma política de aleitamento materno escrita que seja rotineiramente transmitida a toda equipe de cuidados da saúde; capacitar toda a equipe de cuidados da saúde nas práticas necessárias para implementar essa política; informar todas as gestantes sobre os benefícios e o manejo do aleitamento materno; ajudar as mães a iniciar o aleitamento materno na primeira meia hora após o nascimento; mostrar às mães como amamentar e como manter a lactação, mesmo se separadas dos seus filhos; não oferecer aos recém-nascidos bebida ou alimento que não seja o leite materno, a não ser que haja indicação médica; praticar o alojamento conjunto, que consiste em permitir que mães e neonatos permaneçam juntos 24 horas por dia; incentivar o aleitamento materno sob livre demanda; não oferecer bicos artificiais ou chupetas a crianças amamentadas; promover grupos de apoio à amamentação e encaminhar as mães a esses grupos na alta da maternidade.

Identifica-se em pesquisas anteriores realizadas em hospitais que fazem parte da IHAC, a existência de uma política de aleitamento materno normatizada que elevou a taxa de aleitamento (ROSENBERG, 2007). O início do aleitamento materno logo na primeira meia hora após o nascimento, além de elevar os níveis de ocitocina da mãe, favorece a sucção na primeira mamada (MATTHIESEN, 2001). Essas mudanças nas práticas hospitalares, como treinamento dos funcionários, orientação às gestantes, início precoce do aleitamento materno, apoio durante a internação, uso não rotineiro de outros líquidos ou leite artificial, alojamento conjunto, livre demanda, proibição de propaganda e distribuição de fórmulas infantis, bicos e chupetas, contribuem para a redução do desmame precoce, podendo contribuir para diminuição a morbimortalidade infantil (FIGUEIREDO; MATTAR; ABRÃO, 2012). A importância de fazer um acompanhamento adequado após a alta hospitalar mostrou resultados positivos, principalmente quanto à permanência do AME (WRIGHT, 1996).

Já nos hospitais que não tem o título da IHAC, a pesquisa de Lopes et al. (2013) aponta que a falta de uma política incentivadora do aleitamento materno influencia na conduta tanto dos profissionais como das nutrizes. Os resultados desta pesquisa indicam que a maior parte dos profissionais não recebeu treinamento sobre amamentação. Dentre as nutrizes participantes, 100\% informaram não receber orientações sobre alimentação artificial, apenas $20 \%$ das nutrizes receberam informações sobre os sinais de fome do neonato, nenhuma soube citar 
pelo menos 2 desses sinais e 83,3\% foram estimuladas a alimentar seus filhos sob livre demanda (LOPES et al., 2013).

A livre demanda institui que a criança seja amamentada sem horário controlado ou tempo de permanência na mama, sendo o sinal de fome do neonato, o principal indicativo de quando realizar o aleitamento (BRASIL, 2015). Quando o neonato está com fome, ele emite alguns sinais, como aumentar os movimentos dos olhos fechados ou abertos, abrir a boca, esticar a língua e virar a cabeça para procurar a mama, fazer sons suaves de gemido, chupar ou morder as mãos, dedos, coberta, lençol ou outro objeto que entrar em contato com a boca; Chorar alto, curvando-se e ter dificuldade para pegar a mama é considerado um sinal tardio de fome (FUNDO DAS NAÇÕES UNIDAS PARA A INFÂNCIA, 2009).

Um dos pontos importantes a serem considerados para o sucesso na efetivação desta política é a base de profissionais de saúde dominar o conhecimento sobre as práticas do aleitamento materno e estar apta a transferi-lo de modo adequado.

$\mathrm{O}$ desenvolvimento deste estudo justifica-se por identificarmos nos cenários de atenção à saúde que os profissionais abordam pouco os aspectos relacionados à livre demanda e sinais de fome do neonato. Observa-se ainda que, quando abordam os referidos temas, o fazem com fragilidade, pois estabelecem horários rígidos para a mamada do neonato e apontam apenas o choro como reconhecimento do sinal de fome. Desta forma, questionase como os profissionais e nutrizes compreendem livre demanda? E como os profissionais e nutrizes reconhecem os sinais de fome no neonato?

A resposta a essas questões sob a ótica dos profissionais de saúde e nutrizes possibilita compreender como isso reflete-se no processo de amamentação no cotidiano do cenário hospitalar. Desta forma, o objetivo deste estudo foi compreender o conceito de livre demanda e sinais de fome do neonato sob a ótica de nutrizes e profissionais da saúde.

\section{METODOLOGIA}

Foi feito um estudo de campo com abordagem qualitativa, o qual compreende o recorte teórico correspondente ao objeto da investigação buscando identificar crenças, percepções, opiniões e interpretações que os humanos fazem a respeito de si mesmos ou de situações vivenciadas por eles (MINAYO, 2013).

O cenário da pesquisa foi um hospital materno infantil integrado à rede de hospitais "Amigo da Criança", do Ministério da Saúde, desde 2003, que desenvolve ações estabelecidas pelo programa com ênfase no estímulo à amamentação e ao parto humanizado.

Atualmente são realizadas ações de cuidado individual e coletivo nas áreas de Atenção à Saúde da Criança da unidade hospitalar, com capacidade operacional de 100 leitos.

Os sujeitos da pesquisa foram 21 nutrizes e 20 profissionais da saúde que atuam no referido cenário e aceitaram participar deste estudo.

Os dados foram coletados no período de março a maio de 2016 por meio de entrevistas semiestruturadas, que permitem explorar o tema em questão sem se prender à indagação formulada (MINAYO, 2013). Essas entrevistas tinham dados para caracterização dos sujeitos e 2 questões norteadoras: Como os profissionais e nutrizes compreendem livre demanda? e Como os profissionais e nutrizes reconhecem os sinais de fome do bebê?

Os dados coletados foram analisados pela técnica de análise de conteúdo na modalidade temática, que consiste em identificar os núcleos de sentido que compõem as falas, cuja presença ou frequência foi significativo para o objeto investigado (MINAYO, 2013). Essa técnica é composta por três etapas. A pré-análise consiste na seleção de documentos que serão analisados e na retomada das hipóteses e dos objetivos iniciais do estudo. A segunda etapa é a exploração do material, que busca encontrar categorias ou palavras significativas para que o conteúdo de uma fala seja organizado. $\mathrm{Na}$ terceira etapa, o tratamento dos resultados obtidos e interpretação, tem-se a proposta de inferências e realização das interpretações, inter-relacionando-as com o quadro teórico inicial ou sugerindo novas dimensões teóricas e interpretativas.

$\mathrm{O}$ desenvolvimento da pesquisa atendeu às normas nacionais e internacionais de ética em pesquisa envolvendo seres humanos, tendo sido aprovado pelo Comitê de Ética em Pesquisa da Faculdade de Medicina de Marília sob o Parecer n ${ }^{0}$ 1.345.546. 
As entrevistas foram gravadas e transcritas na íntegra com o consentimento dos sujeitos que aceitaram participar desta pesquisa. Para garantir o sigilo e anonimato dos sujeitos participantes, suas falas foram identificadas por "P" para profissionais e "N" para nutrizes, acompanhadas numericamente como, por exemplo, "P1", "P2", "N1", "N2", sucessivamente.

\section{RESULTADOS}

Todas as nutrizes participantes têm idade superior a dezoito anos, porém apenas 10 relataram ter Ensino Médio Completo. Dentre essas, somente 1 está cursando o Ensino Superior. Dez relataram seu estado civil ser solteiro e, em relação aos dados obstétricos, 6 eram primíparas, todas realizaram as consultas de prénatal e só 2 participaram de cursos para gestantes.

Os profissionais participantes têm idade acima de dezoito anos, 7 relataram trabalhar no Hospital Materno Infantil há mais de 20 anos e apenas 2 trabalham na unidade há menos de 5 anos. De todos os profissionais entrevistados, somente 2 não participaram do curso de capacitação da IHAC. Evidencia-se o perfil de profissionais do sexo feminino na unidade.

\subsection{EM BUSCA DO SIGNIFICADO DE LIVRE DEMANDA}

A maioria das nutrizes participantes deste estudo não souber responder o significado de livre demanda ou, quando tentaram explicá-lo, associaram-no a intervalos de horários pré-determinados, como mostram as falas abaixo:

\footnotetext{
Não sei, não. [...] $\left(\mathrm{N}_{4} ; \mathrm{N}_{5} ; \mathrm{N}_{10} ; \mathrm{N}_{11}\right.$; $\mathrm{N}_{14} ; \mathrm{N}_{15}$ )

[...] Eu dou pra ela de 3 em 3 horas $\left(\mathrm{N}_{1} ; \mathrm{N}_{12} ; \mathrm{N}_{13}\right)$

[...] de 2 em 2 horas. Eu acordo ela e dou o mamazinho. $\left(\mathrm{N}_{2} ; \mathrm{N}_{11}\right)$

[...] O aleitamento materno tem que ser dado de 3 em 3 horas e que até o sexto mês o bebe não precisa de mais nada, que só o leite é suficiente. $\left(\mathrm{N}_{8}\right)$

Se ele estiver dormindo, de 3 em 3 horas, mas se ele estiver acordado, ele pode mamar o quanto ele quiser. $\left(\mathrm{N}_{7}\right)$

[...] Agora tem que ser pelo menos 2 em 2 horas, depois de 3 em 3 e assim vai aumentando. $\left(\mathrm{N}_{20}\right)$
}

Observa-se nos relatos das nutrizes e dos profissionais que o padrão rígido de horários para amamentar é reforçado pelas orientações de profissionais da saúde, que referem em seus relatos a preocupação em manter um horário regular de mamadas para garantir o ganho ponderal, a hidratação e a glicemia da criança.

\begin{abstract}
Não... As enfermeiras falaram pra mim que eu tinha que tá amamentando, não esperar ela ter fome... em 2 em 2 horas, em 3 em 3 horas amamentar ela. $\left(\mathrm{N}_{2}\right)$

Ela falou pra mim que se chorasse, que o certo é de 3 em 3 h, mas que se chorasse antes, eu podia dar, que o leite não faz mal, não é pra dar chá de camomila, não precisa dar água, chá, suco, nada dessas coisas até os seis meses. $\left(\mathrm{N}_{4}\right)$

Ah, que nem elas explicaram. Tem que ser de 3 em 3 horas pra poder a criança pegar peso e manter a glicemia. $\left(\mathrm{N}_{6}\right)$

Que pra dar o leite pra ele é de 3 em 3 horas. $\left(\mathrm{N}_{14}\right)$

Dizem que é de 3 em 3 horas, né. $\left(\mathrm{N}_{15}\right)$

Não tem tempo, horário, nada estipulado, de acordo com a necessidade. No máximo de 3 em 3 horas [...] $\left(\mathrm{P}_{14}\right)$

Toda vez que o neonato solicitar, não deixar passar de 3 horas. $\left(\mathrm{P}_{11}\right.$; $\mathrm{P}_{12}$ )

A livre demanda seria a hora que o neonato chora. [...] e aí a gente orienta a mãe a não deixar muito tempo sem mamar, mais que $3 \mathrm{~h}$. [...] que aí pode correr um risco de hipoglicemia. $\left(\mathrm{P}_{5}\right)$

[...] Se passar de 3 horas e neném não estiver acordado, você tem que acordar porque ele desidrata. [...] $\left(\mathrm{P}_{17}\right)$
\end{abstract}

Por outro lado, os profissionais atribuem dificuldades ao comportamento materno, como a resistência em amamentar durante o período noturno.

\footnotetext{
A livre demanda é o tanto que a criança quer mamar. [...] $\mathrm{O}$ certo seria assim, mamar a cada $3 \mathrm{~h}[\ldots]$. A gente sempre orienta colocar, por mais que elas estejam cansadas, resistentes, principalmente à noite. A noite é muito complicado, elas querem dormir, a criança quer mamar. Então, assim, é bem complicado, principalmente à noite $\left(\mathrm{P}_{7}\right)$
} 
Algumas nutrizes e a maioria dos profissionais explicaram o significado de livre demanda por meio das próprias solicitações do neonato em relação à mamada e sem horários rígidos para atender às necessidades de fome da criança.

O neonato poder mamar a hora que ele quiser e pelo tempo suficiente $\left(\mathrm{N}_{3}\right)$ Ai eu coloco ela e deixo ela mamar. [...] Sempre que ela pede. $\left(\mathrm{N}_{16}\right)$

[...] Não contava no relógio. Quando sentia fome, eu amamentava. $\left(\mathrm{N}_{17}\right)$

[...] Eu dou sempre que vejo ela procurando, procurando com a boca, quando ela começa a chorar, procurar o peito, aí eu coloco ela. $[\ldots]\left(\mathrm{N}_{18}\right)$

Eu dou sempre, tipo assim, chorou, vê que tá com fome, eu dou. $\left(\mathrm{N}_{10}\right)$

Toda vez que ela pede. $\left(\mathrm{N}_{21}\right)$

[...] quando a criança tem fome, ela solicita e a mãe amamenta. $\left(\mathrm{P}_{1} ; \mathrm{P}_{9}\right)$

A livre demanda é diretamente proporcional à própria necessidade da criança $[. .$.$] É a criança quem deter-$ mina o tempo e não a mãe $\left(\mathrm{P}_{2} ; \mathrm{P}_{19}\right.$; $\mathrm{P}_{20}$ )

Sem horário de intervalo fixo, sem tempo de mamada fixo. É no horário do neonato, na verdade. $\left(\mathrm{P}_{3} ; \mathrm{P}_{13}\right.$; $\left.\mathrm{P}_{15} ; \mathrm{P}_{17} ; \mathrm{P}_{18}\right)$

Eu acho que tem que ser a todo momento que o bebe ter vontade [...] no momento em que o nenê mostrou algum sinal de que tá com fome. $\left(\mathrm{P}_{4} ; \mathrm{P}_{6} ; \mathrm{P}_{10} ; \mathrm{P}_{12} ; \mathrm{P}_{10}\right)$

O desconhecimento sobre 0 assunto foi justificado ainda, por parte das nutrizes, pela falta de informações vindas de profissionais da saúde tanto no pré-natal como na maternidade, o que pode ser conferido nos relatos abaixo:

[...] não, sobre isso não $\left(\mathrm{N}_{1}\right)\left(\mathrm{N}_{9}\right)$ Não, ainda não conversou. $\left(\mathrm{N}_{11}\right)$ Não, só li na carteirinha de gestante e explica essas coisas. [...] $\left(\mathrm{N}_{14}\right)$

\subsection{RECONHECIMENTO DOS SINAIS DE FOME DO NEONATO}

Os relatos da maioria das nutrizes e de vários profissionais entrevistados evidenciam que o choro é o principal ou o primeiro sinal de fome que a criança demonstra.
[...] Eles choram pra mamar e eu vou contando de 3 em 3 horas. $\left(\mathrm{N}_{1} ; \mathrm{N}_{10}\right.$; $\mathrm{N}_{17}$ )

Quando ele chora muito [...] E acordo ele de 3 em 3 h que a enfermeira falou de 3 em 3 h acordar ele pra dar mama mesmo se ele não estiver chorando. [...] ele fica mordendo a mão e procurando algum lugar pra colocar a boca... $\left(\mathrm{N}_{3}\right)$

Eu só dou realmente quando ela começa a chorar, resmungar muito, ficar muito chupando a mãozinha [...] Quando não para mais de chorar, aí eu dou o peito pra ela mamar. $\left(\mathrm{N}_{4}\right)$ [...] pelo choro, a boca, quando começa a abrir e procurar o peito. É isso. $\left(\mathrm{N}_{8} ; \mathrm{N}_{11} ; \mathrm{N}_{12} ; \mathrm{N}_{13}\right)$

[...] Porque os meus começam a chorar. [...] É mais na base do choro. $\left(\mathrm{N}_{9} ; \mathrm{N}_{15} ; \mathrm{N}_{16} ; \mathrm{N}_{20} ; \mathrm{N}_{21}\right)$

Cada vez que o neonato chora, que o neonato acorda, que o neonato tá agitado. [...] que o neonato chora, principalmente $\left(\mathrm{P}_{1} ; \mathrm{P}_{2} ; \mathrm{P}_{5} ; \mathrm{P}_{7} ; \mathrm{P}_{8} ; \mathrm{P}_{10}\right.$; $\left.\mathrm{P}_{15} ; \mathrm{P}_{17} ; \mathrm{P}_{19}\right)$

Há profissionais que acreditam que não é possível reconhecer os sinais de fome na criança porque o choro pode ter outros significados.

Não tem como você reconhecer [...] nem sempre quando ele chora, é fome $[. .$.$] Você tem que oferecer, se$ ele pegar, é porque ele tá com fome. $\left(\mathrm{P}_{6}\right)$

Poucas nutrizes souberam reconhecer outros sinais de fome do seu filho que antecedem o choro e ordená-los corretamente. Todavia, metade dos profissionais entrevistados demonstrou conhecimento sobre tal aspecto, destacando a importância de não deixar chegar na última manifestação do recém-nascido para propiciar a amamentação bem-sucedida.

Ele começa a chupar a mão e fica nervoso... $\left(\mathrm{N}_{5}\right)$

Que ele fica procurando o peito, chorando demais. [...] Fica comendo os dedinhos. $\left(\mathrm{N}_{-}\right)$

[...] Ela fica com a boquinha aberta, chupando a mão, às vezes, virando o pescoço. Aí eu vejo que ela tá procurando e eu dou. Não é mais pelo horário, é mais quando eu vejo ela procurando. $\left(\mathrm{N}_{18}\right)$

[...] o sinal de procura, ou ele vai na mão, começa a morder a mãozinha 
ou qualquer coisa que passa em frente da boquinha dele, cobertor, roupinha. Tudo o que tiver perto, ele vai na procura e tenta sugar. Às vezes o neonato fica mais agitado, começa a se movimentar muito no berço, a mãozinha, a perninha, né... Ele começa a ficar mais agitadinho. Aí, por último, normalmente ele começa a chorar, a hora que ele já tá muito irritado, que ele já procurou, que ele... né, e ninguém deu atenção pra ele, aí um dos sinais é o choro também, que eu normalmente falo pra mães não esperar chorar [...]se ele estiver chorando, acalmar ele primeiro pra depois amamentar, porque senão depois não dá certo. $\left(\mathrm{P}_{3} ; \mathrm{P}_{11} ; \mathrm{P}_{20}\right)$

[...] nem sempre é o choro. Então, às vezes ele pode tá mordendo a mãozinha, ele pega o paninho e começa a procurar o paninho como se fosse $o$ peito. [...] às vezes ele fica procurando, fazendo gestos com a boca, tipo um peixinho mesmo procurando o alimento. Eu falo pra ela que ele põe a mãozinha na boca e fica sugando, outro sinal de fome é o choro $\left(\mathrm{P}_{4} ; \mathrm{P}_{14}\right)$

O neonato acorda, ele fica inquieto, ele fica muito agitado, ele tenta abocanhar alguma coisa próximo a boquinha, se é roupinha ou ele leva a mãozinha. Ele passa a linguinha entre os lábios e o último de fome é o choro, último sinal. $\left(\mathrm{P}_{9} ; \mathrm{P}_{12} ; \mathrm{P}_{13}\right.$; $\mathrm{P}_{16} ; \mathrm{P}_{18}$ )

Embora algumas nutrizes soubessem reconhecer os sinais de fome da criança, a prática da rotina hospitalar instituída no serviço de saúde interfere na promoção do aleitamento materno em livre demanda, levando-as a amamentarem os filhos obedecendo horários regulares e padronizados.

[...] Quando ele começa a ficar mastigando um pouquinho a boquinha e dos intervalos aqui. $\left(\mathrm{N}_{14}\right)$

\section{DISCUSSÃO}

As limitações deste estudo estão relacionadas ao tipo de abordagem utilizada nesta pesquisa, pois esta limita-se a generalizações dos resultados. No entanto, foi identificado entre as nutrizes dificuldades para atribuir o significado adequado à livre demanda e tanto elas quanto os profissionais referem o choro como principal sinal de fome da criança. Já a maioria dos profissionais participantes demonstraram conhecimento sobre o significado de livre demanda, mas mostram-se inseguros ao aplicar tal conhecimento, pois orientam as mulheres a seguirem horários padronizados para as mamadas.

Os resultados encontrados neste estudo são corroborados por outras pesquisas, como um estudo realizado em um Hospital Amigo da Criança, no qual as nutrizes revelam que nem sempre o nascimento de uma criança neste hospital traz benefícios. Apesar de reconhecerem a importância dos profissionais de saúde no processo de amamentação, referem que suas condutas e atitudes, às vezes, podem não repercutir positivamente nesta prática (ORSO; MAZZETTO; SIQUEIRA, 2016).

Apesar da maioria dos profissionais participantes desta pesquisa terem realizado o curso de capacitação da IHAC, no qual o tema Aleitamento Materno é abordado, muitos deles, mesmo que saibam a definição de livre demanda, preocupam-se em estimular os horários rígidos com a finalidade de manter a glicemia, a hidratação e o ganho ponderal da criança. Esta insegurança quanto à eficácia da livre demanda acaba tornando-se uma barreira no processo de aconselhamento em amamentação direcionado às nutrizes (BRANDÃO et al., 2012).

Identifica-se neste estudo, assim como em outras pesquisas, que há deficiência na atuação dos profissionais de saúde por apresentarem fragilidades no processo de comunicação com as nutrizes devido ao distanciamento entre o conhecimento e o fazer. Destaca-se que a comunicação adequada é fundamental para garantir a clareza nesse processo de transmissão de informações às nutrizes (BRANDÃO et al., 2012).

A fragilidade identificada no processo de comunicação entre a nutriz e o profissional também pode ser explicada pela organização da prática da rotina hospitalar, que interfere na promoção do aleitamento materno exclusivo em livre demanda. Identificou-se que algumas nutrizes, além de atenderem às solicitações dos neonatos para a mamada, são orientadas pelos profissionais a seguirem os horários padronizados no serviço de saúde. Tais resultados reforçam a necessidade 
de reorganização da prática e da rotina hospitalar existente (SIQUEIRA; COLLI, 2013).

Evidenciou-se ainda, nas falas das nutrizes participantes desta pesquisa, que a prática de aconselhamento no pré-natal ou na maternidade dá-se de forma incipiente, pois referiram que os profissionais abordam pouco ou não abordam orientações sobre os aspectos aqui estudados. Há outros estudos desenvolvidos em unidades de estratégia de saúde da família que também apontam a falta incentivo ao aleitamento materno no prénatal (QUEIROZ; SHIMO; NOZAWA, 2011). Em consultas particulares, obstetras têm um papel fundamental nesse processo de estímulo ao aleitamento materno, apoiando e tratando possíveis complicações que possam surgir para que a nutriz alcance seu objetivo de amamentar (STUEBE, 2014).

Emerge nos relatos dos profissionais participantes uma prática de cuidado centrado em aspectos biológicos. Para Serra e Scochi (2004), a assistência prestada às nutrizes tem como foco o biológico, carente na sistematização relacionada ao aleitamento materno, sobressaindo características pessoais do profissional com repasse de informações fragmentadas, muitas vezes desprovidas de embasamento científico atualizado.

A prática fragmentada do aleitamento materno pode ser explicada pela falta de capacitação dos profissionais, que orientam de acordo com os conhecimentos adquiridos durante sua formação acadêmica, resultando em uma ação desarticulada (QUEIROZ; SHIMO; NOZAWA, 2011).

Esta lacuna do conhecimento sobre livre demanda e sinais de fome da criança pode ser consequente de uma falha que ainda existe na formação profissional e que deve ser trabalhada a fim de supri-la, já que a temática da amamentação é vista sem grande importância em alguns espaços de aprendizado (PRATES; SCHMALFUSS, 2014).

Acredita-se que o profissional de saúde exerce papel importante na promoção do aleitamento materno, apoiando e informando a mulher durante o pré-natal, alojamento conjunto, puericultura e campanhas de incentivo ao aleitamento materno (ANDRADE et al., 2014).

Neste estudo, identificou-se que além da maioria das nutrizes, alguns profissionais reconhecem apenas o sinal tardio de fome do lactente: o choro. Acredita-se que diante da dificuldade que as nutrizes apresentam para acalmar o filho, acabam introduzindo as fórmulas lácteas, o que contribui para o desmame precoce. Ainda diante da preocupação em atender à necessidade nutricional do filho, ofertam o seio materno em horários determinados ou o acordam para amamentar (VARGAS et al., 2016).

Para que a livre demanda seja uma prática segura, é necessário reconhecer os sinais de fome oportunamente, isto é, prévios ao lactente apresentar o último sinal, que é o choro. Um estudo que aborda o conhecimento das mães sobre os sinais de fome infantil foi finalizado nos Estados Unidos em 2005 e contou com 197 mães, que foram acompanhadas durante 24 meses, iniciados no pré-natal. Referido estudo evidencia que as nutrizes que reconhecem os sinais de fome infantis têm maior probabilidade de obter sucesso no aleitamento materno exclusivo até o sexto mês, dando continuidade por um período maior do que as que não são instruídas sobre este tema (KANDIAH; BURIAN; AMEND, 2011).

A escolaridade materna também interfere na manutenção do aleitamento materno e na compreensão do que é o aleitamento materno exclusivo (DIOGO; SOUZA; ZOCCHE, 2011). Neste estudo, é notável que quase metade das nutrizes entrevistadas não tem a escolaridade mínima adequada para a idade. Assim, é essencial que os profissionais tenham alternativas de cuidado com papel decisivo, atuando de modo sensível e apropriado à realidade das mulheres (PRATES; SCHMALFUSS, 2014).

Para uma gestão de cuidados e promoção do aleitamento materno adequada, é fundamental que esta seja feita com a participação da nutriz e do parceiro, identificando e respeitando o modo de organização da família (MUÑOZ, 2011). Diante disso, é necessário que o profissional aproxime-se do modo de vida familiar da nutriz para traçar estratégias que sensibilize e empodere a família quanto às práticas da amamentação (PRATES; SCHMALFUSS, 2014), pois os saberes maternos transmitidos por familiares são um fator determinante para a amamentação efetiva (DIOGO; SOUZA; ZOCCHE, 2011).

Para tanto, o profissional de saúde deve estar preparado e seguro para lidar com as dificuldades que as nutrizes vivenciam no processo de amamentação, 
acolhendo suas inseguranças e fornecendo-lhe informações consistentes (TOMA; REA, 2008; SILVA, 2015). Além disso, é oportuno considerar que uma prática de amamentação bem-sucedida depende de políticas governamentais adequadas e do apoio de toda a sociedade (ANDRADE et al., 2014).

\section{CONSIDERAÇÕES FINAIS}

Os resultados deste estudo evidenciam que as nutrizes desconhecem o real significado de livre demanda e apontam o choro como o principal sinal de fome da criança. Identificou-se também que as nutrizes que conseguiram relatar claramente o significado de livre demanda, bem como descrever os sinais de fome, referem que são influenciadas pela conduta do profissional e pela prática assistencial instituída no serviço de saúde, o que as levam a amamentar em horários regulares.

Em relação aos profissionais, verificou-se que têm o conhecimento sobre o objeto investigado, mas apresentam insegurança ao aplicar o saber adquirido e desenvolvem ações centradas em aspectos biológicos e pautados na rotina hospitalar, mostrando o quanto é importante um processo de capacitação permanente.

Verifica-se que o despreparo dos profissionais pode influenciar negativamente a decisão da nutriz em manter o aleitamento materno exclusivo em livre demanda. Desta forma, fica evidente a necessidade não só do preparo profissional, mas também de ações que proporcionem o empoderamento da mulher no ciclo gravídico puerperal.

\section{REFERÊNCIAS}

BRANDÃO, E. C.; SILVA, G. R. F.; GOUVEIA, M. T. O.; SOARES, L. S. Caracterização da comunicação no aconselhamento em amamentação. Rev. Eletr. Enf. [Internet]., v. 14, n. 2, p. 355-65, abr.jjun. 2012. Disponível em: http://dx.doi.org/10.5216/ree.v14i2.12748. Acesso em: 25 jun. 2016.

BRASIL. Ministério da Saúde. II Pesquisa de prevalência de Aleitamento Materno nas capitais brasileiras e Distrito Federal. Brasília, 2009.
BRASIL. Ministério da Saúde. Iniciativa Hospital Amigo da Criança. Brasília, 2011.

BRASIL. Ministério da Saúde. Pesquisa de prevalência de Aleitamento Materno em municípios brasileiros. Brasília, 2010.

BRASIL. Ministério da Saúde. Secretaria de Atenção à Saúde. Departamento de Atenção Básica. Saúde da criança: aleitamento materno e alimentação complementar / Ministério da Saúde, Secretaria de Atenção à Saúde, Departamento de Atenção Básica. 2. ed. Brasília: Ministério da Saúde, 2015.

DIOGO, E. F.; SOUZA, T.; ZOCCHE, D. A. Causas do desmame precoce e suas interfaces com a condição socioeconômica e escolaridade. Enfermagem em Foco, Salvador, v. 2, n. 1, p. 10-13, 2011.

FIALHO F. A.; LOPES, A. M.; DIAS, I. M. A. V.; SALVADOR, M. Fatores associados ao desmame precoce do aleitamento materno. Rev. Cuid., Catanduva, v. 5, n. 1, p. 670-8, 2014.

FIGUEREDO, S. F.; MATTAR, M. J. G.; ABRAO, A. C. F. V. Iniciativa Hospital Amigo da Criança: uma política de promoção, proteção e apoio ao aleitamento materno. Acta Paul. Enferm., São Paulo, v. 25, n. 3, p. 459-463, 2012.

FUNDO DAS NAÇÕES UNIDAS PARA A INFÂNCIA. Iniciativa Hospital Amigo da Criança: revista, atualizada e ampliada para o cuidado integrado: módulo 3: promovendo e incentivando a amamentação em um Hospital Amigo da Criança: curso de 20 horas para equipes de maternidade. Brasília: Ministério da Saúde, 2009.

KANDIAH, J.; BURIAN, C.; AMEND, V. Teaching new mothers about infant feeding cues may increase breastfeeding duration. Food and Nutrition Sciences, Muncie, v. 2, p. 259-264, 2011.

LOPES, S. S.; LAIGNIER, M. R.; PRIMO, C. C.; LEITE, F. M.C. Iniciativa Hospital Amigo da Criança: avaliação dos dez passos para o sucesso do aleitamento materno. Rev. Paul. Pediatr., São Paulo, v. 31, n. 4, p. 488-493, 2013. 
MATTHIESEN, A. S.; RANSJÖ-ARVIDSON, A. B.; NISSEN, E.; UVNÄS-MOBERG, K. Postpartum maternal oxytocin release by newborns: effects of infant hand massage and sucking. Birth, Boston, v. 28, n. 1, p. 13-19, 2001.

MINAYO, M. C. S. O desafio do conhecimento: pesquisa qualitativa em saúde. 13. ed. São Paulo: Hucitec, 2013.

MUÑOZ, L. C. Lactancia materna y gestión del cuidado. Rev. Cubana Enfermer., Ciudad de la Habana, v.27, n. 4, sep./dic. 2011.

ORSO L. F.; MAZZETTO F. M. C.; SIQUEIRA F. P. C. Percepção de mulheres quanto ao cenário de cuidado em saúde na promoção do aleitamento materno. Revista Recien, São Paulo, v. 6, n. 17, p. 3-12, 2016.

PRATES, L. A.; SCHMALFUSS, J. M.; LIPINSKI, J. M. Amamentação: a influência familiar e o papel dos profissionais de saúde. Rev. Enferm. UFSM, Santa Maria, v. 4, n. 2, p. 359-367, 2014.

QUEIROZ, P. H.; SHIMO A. K., NOZAWA M. R. Enfermeiras da atenção básica na promoção do aleitamento materno. Rev. Pesqui. Cuid. Fundam., Rio de Janeiro, v.1, n. 2, p.1879-1888, 2011.

ROSENBERG, K. D.; STULL, J. D.; ADLER, M. R.; KASEHAGEN, L. J.; CRIVELLI-KOVACH, A. Impact of hospital polices on breastfeeding outcomes. Breastfeed Med., New Rochelle, v. 3, n. 2, p. 110-116, 2007.

SERRA, S. O. A.; SCOCHI, C. G. S. Dificuldades maternas no processo de aleitamento materno de prematuros em uma UTI neonatal. Rev. Latino-Am. Enfermagem, Ribeirão Preto, v. 12, n. 4, p. 597-605, julho/ago. 2004.

SILVA, C. F. Contribuição de intervenção próaleitamento materno nos primeiros quatro meses pós-parto para a manutenção da amamentação por dois anos ou mais: ensaio clínico randomizado com mães adolescentes e avós maternas. [Dissertação]. Porto Alegre (RS): Universidade Federal do Rio Grande do Sul; 2015.

SIQUEIRA, F. P. C.; COLLI, M. Prevalência do contato precoce entre mãe e recém-nascido em um hospital amigo da criança. Rev. Enferm. UFPE on line, Recife, v. 7, n. 11, p. 6455-61, nov. 2013.

STUEBE, A. M. Formas de facilitar que la mujer alcance sus metas de lactancia materna. Obstetrics \& Gynecology, Chapel Hill, v. 123, p. 643-652, 2014.

TOMA, T. S.; REA, M. F. Benefícios da amamentação para a saúde da mulher e da criança: um ensaio sobre as evidências Benefits of breastfeeding for maternal and child health: an essay on the scientific evidence. Cad. Saúde Pública, Rio de Janeiro, v. 24, n. 2, p. 235-246, 2008.

VARGAS, P. B.; VIEIRA, B. D. G.; QUEIROZ, A. B. A.; ALVES, V. H.; AGUIAR, R. C. B.; RODRIGUES, D. P. Experiências de puérperas na identificação de sinais de fome do recémnascido. Revista Baiana de Enfermagem, Salvador, v. 30, n. 1, p. 335-343, jan./mar. 2016.

VENANCIO, S. I.; ESCUDER, M. M. L.; SALDIVA, S. R. D. M.; GIUGLIANI, E. R.J. A prática do aleitamento materno nas capitais brasileiras e Distrito Federal: situação atual e avanços. J. Pediatr. (Rio J.), Rio de Janeiro, v. 86, n. 4, p. 317-324, ago. 2010.

WORLD HEALTH ORGANIZATION, United Nations Children's Fund. Innocent Declaration. Florença: UNICEF/OMS, 1990.

WORLD HEALTH ORGANIZATION. Evidence for the ten steps to successful breastfeeding. Geneva, 1998.

WORLD HEALTH ORGANIZATION. The optimal duration of exclusive breastfeeding: a systematic review. Geneva, 2002.

WRIGHT, A.; RICE, S; WELLS, S. Changing hospital practices to increase the duration of breastfeeding. Pediatrics, Evanston, v. 97, n. 5, p. 669-675, 1996.

Recebido em: 20 de junbo de 2017 Aceito em: 10 de agosto de 2017 